University of Nebraska - Lincoln

DigitalCommons@University of Nebraska - Lincoln

The Influence of Schematic Knowledge on Contradictory versus Additive Misinformation: False Memory for Typical and Atypical Items

\author{
Robert J. Nemeth \\ University of Nebraska-Lincoln, rnemeth@uwsp.edu \\ Robert F. Belli \\ University of Nebraska-Lincoln, bbelli2@unl.edu
}

Follow this and additional works at: https://digitalcommons.unl.edu/psychfacpub

Part of the Psychiatry and Psychology Commons

Nemeth, Robert J. and Belli, Robert F., "The Influence of Schematic Knowledge on Contradictory versus Additive Misinformation: False Memory for Typical and Atypical Items" (2006). Faculty Publications, Department of Psychology. 493.

https://digitalcommons.unl.edu/psychfacpub/493

This Article is brought to you for free and open access by the Psychology, Department of at DigitalCommons@University of Nebraska - Lincoln. It has been accepted for inclusion in Faculty Publications, Department of Psychology by an authorized administrator of DigitalCommons@University of Nebraska - Lincoln. 


\title{
The Influence of Schematic Knowledge on Contradictory versus Additive Misinformation: False Memory for Typical and Atypical Items
}

\author{
Robert J. Nemeth and Robert F. Belli \\ Department of Psychology, University of Nebraska-Lincoln, USA \\ Correspondence: Robert J. Nemeth, current address: Department of Psychology, University of Wisconsin- \\ Stevens Point, Science-Room D-240, Stevens Point, WI 54481, USA. E-mail rnemeth@uwsp.edu
}

\begin{abstract}
In the current study, we examined the influence of schema consistency on contradictory and additive misinformation. Sixty-four participants were shown a series of still photographs of common scenes (e.g., a kitchen), were later exposed to narratives containing misinformation, and were then tested on their memory of the photographic scenes. In addition, participants were asked to reflect on their phenomenological experience of remembering by giving remember/know responses. Participants reported greater false memory for schema-inconsistent items than schema-consistent items. The findings failed to replicate Roediger, Meade, and Bergman (2001). Explanations for the discrepant findings are discussed.
\end{abstract}

The research of Elizabeth Loftus and her colleagues has strongly influenced our understanding of memory. Some of her earliest and most pervasive contributions have resulted from the delineation of the misinformation effect (Loftus, 1975; Loftus, Miller, \& Burns, 1978; Loftus \& Palmer, 1974). One of the most consistent observations in cognitive psychology involves participants falsely remembering misinformation provided to them after some witnessed event (Belli, Lindsay, Gales, \& McCarthy, 1994; Lindsay, 1990; Loftus, Donders, Hoffman, \& Schooler, 1989; Zaragoza \& Lane, 1994). These observations have had tremendous implications in applied settings, especially with regard to the reliability of eyewitnesses and with the nature of autobiographical remembering (Belli \& Loftus, 1996; Lindsay, 1994; Zaragoza, Belli, \& Payment, in press).

Despite the richness of work on the misinformation effect, very little is known about the role that schematic knowledge plays in the inducement of false memories that result from being misled. Research has indicated that schematic knowledge guides memory retrieval of common visual scenes (Brewer \& Treyens, 1981; Friedman, 1979). In these experiments, participants are exposed to schema-consistent items, such as bookshelves in an academic office and schema-inconsistent items, such as a picnic basket in the same office. Just as with text passages, the research on visual scenes has also shown that expectations based on previous knowledge affect memory. However, the particular pattern of results depends, in part, on the type of memory test given. With recognition tests, participants are more accurate at discriminating be- 
tween old and new items if they are of low typicality (i.e., schema inconsistent) than if they are of high typicality (schema consistent), the aptly named typicality effect (Erdfelder \& Bredenkamp, 1998). In addition, participants will falsely recognize the presence of schema-consistent items that were never presented. Thus, people have been shown to falsely recognize typical information even when not misinformed. With free recall tests, participants remember more schema-consistent items than schema-inconsistent items as schematic knowledge guides the retrieval process (Brewer \& Treyens, 1981).

Roediger et al. (2001) have investigated the role of schematic knowledge in a variation of the traditional misinformation effect experiment. In what they call the 'Social Contagion' paradigm (also see Meade \& Roediger, 2002), participants are led to believe that they are participating in a memory experiment with a fellow undergraduate. Unbeknownst to the subject, the fellow undergraduate is really a confederate of the experimenter. After viewing photographs of simple scenes (e.g., a kitchen, a toolbox, a bedroom, etc.), the participant and confederate complete a session of collaborative recall, in which each person takes turns recalling one item from the scene in question. The key manipulation in this experiment is that the confederate deliberately feeds misinformation to the participant of items that were never present in the scene. Afterwards, participants are engaged in an individual recall session in which they attempt to recall as many items from the scenes as possible. The potency of the misinformation effect depends on whether the misinformed items were high in schema consistency (such as screws in a toolbox, termed as 'high expectancy' items) or low in schema consistency (such as a ruler in a toolbox, termed as 'low expectancy' items). Roediger et al. found a stronger social contagion misinformation effect for high-expectancy items in comparison to low-expectancy ones, after controlling for false recall of the same items when they were not presented as misinformation.

Roediger et al.'s (2001) manipulation of misinformation through the social contagion paradigm only included suggested details that added to the previously viewed scenes. Although this approach exemplifies much research on the misinformation effect, there is also a substantive degree of research that examines the misinformation effect when suggested items directly contradict items seen in an original event (e.g., a suggested stop sign in the place of a yield sign). Recent research by Frost (2000) has sought to elucidate the relative effects of additive versus contradictory misinformation on the subjective experience of false memory. Utilizing Tulving's (1985) remember/know procedure, which requires participants to introspect as to whether they can explicitly remember the details of a recalled event or whether they just know that a detail was present in an event, Frost found that participants were more likely to falsely remember additive misinformation as having occurred in the event than contradictory misinformation but only after a 1-week retention interval as opposed to a 10-minute retention interval. Frost speculated that participants must have detected the contradiction at some level, whether conscious or not, when given contradictory misinformation and thus, were less likely to indicate a remember response for this type of misinformation. Importantly, Frost did not manipulate item typicality in these experiments.

In the following experiment we conducted an exploratory investigation of the interaction between the type of misinformation (i.e., additive vs. contradictory) and whether the critical items were schema consistent or schema inconsistent (i.e., high typicality vs. low typicality) on participants' false remember and know responses. In particular, we were interested in replicating Roediger et al.'s (2001) findings with regard to schematic influence on false memory, but within a traditional misinformation 
effect paradigm versus the social contagion paradigm. If schematic knowledge guides memory retrieval, misinformation that is consistent with the schema should produce greater false memory than misinformation that is inconsistent. Therefore, we predicted that misinformation that is highly typical would produce greater false memory than low-typicality misinformation. Furthermore, low-typicality misinformation may make contradictory misinformation easier to detect, producing greater false memory for additive misinformation of highly typical items.

\section{Method}

\section{Participants}

Sixty-four undergraduates from a large Midwestern university participated in the experiment for extra-course credit. They ranged in age from 18 to 36 with a mean age of 19.7 years. Forty-three women (67\%) and 21 men (33\%) participated in the experiment.

\section{Materials}

Eight sets of critical items (four high typical and four low typical) were created in order to test memory for the visual scenes, as well as to introduce misinformation. Critical items from two high-typical sets and two low-typical sets were each presented in one of two critical scenes. The critical items are listed in Appendix A according to typicality and the critical scene in which they were presented.

Seven digital color photographs depicted two critical and five filler scenes. The filler scenes consisted of an automobile body shop, a bedroom, a computer lab, a laundry room, and a classroom. The critical scenes consisted of a kitchen and living room of an apartment. The digital photographs were presented on Windows-based computers with 17" monitors. The experimental display was created using Media Lab software. The photographs were sized so that they filled approximately $90 \%$ of the screen.

There were four versions created for each critical scene so as to depict one hightypical item and one low-typical item in each version, counterbalancing each critical item across sets and scenes. Figure 1 shows a representative example of one version of the living room critical scene. Item typicality ratings were assessed in a pilot test of the photographs.

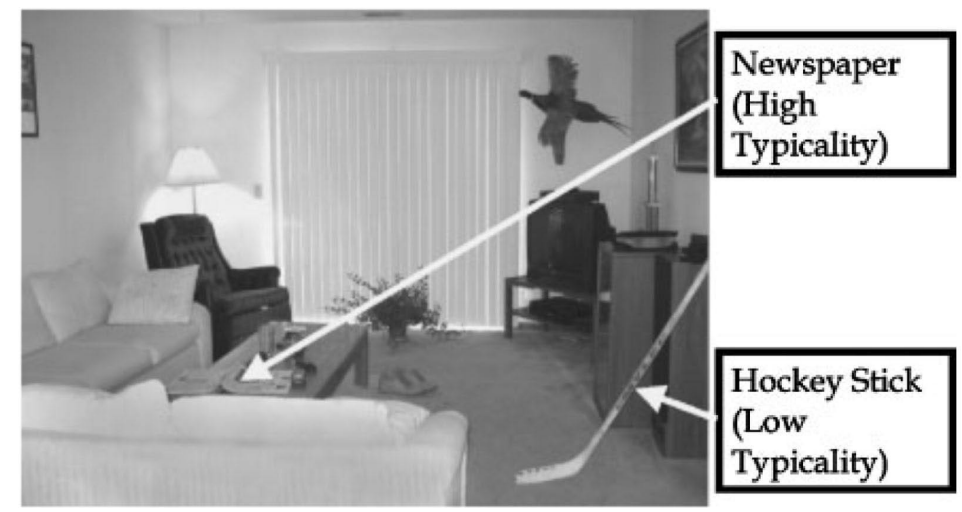

Figure 1. An example of the critical living room scene with high-and low-typicality items indicated 
Twenty-four participants, who did not participate in the experiment, rated each item in terms of typicality on a 7-point Likert-type scale. They were asked, 'How typical is this item in this scene?' Each item was highlighted with an arrow to facilitate identification. The participants' ratings indicated that high typicality items were perceived as more typical $(M=6.38, S D=0.44)$ than the low typicality items $(M=2.78$, $S D=1.15), t(23)=15.41, p<0.01$. Individual typicality ratings for each critical item can be seen in Appendix A.

Five narratives that described various scenes were created in order to introduce misinformation. An example of the narrative for the Living Room Scene can be found in Appendix B. Two of the narratives described scenes that were novel (i.e., not shown in photographs; a backyard and a bathroom). Three of the narratives described scenes that were presented as photographs in the first phase of the experiment, onefiller scene and two scenes containing critical items. The narratives ranged between 304 and 375 words ( $M=333$ words). Eight versions of narratives for each scene were created; each version contained two items of misinformation, one high-typical item, and one low-typical item. Different versions of the narratives were created in order to completely counterbalance the shown and misled items across conditions.

A 20-item cued recall test was used to test participants' memory of the photographic scenes displayed in the event phase of the experiment. Four questions were asked for each of five scenes in the following order: laundry room, kitchen, bedroom, living room, and classroom. For the critical scenes, two questions referred to critical items that were present in the scene (i.e., one high-typicality item and one low-typicality item) and two questions referred to critical items that were absent from the scene (i.e., again one high-typicality item and one low-typicality item). Questions were written so as to cue the category of the item as well as its location within the context of the scene (e.g., 'What was the SMALL KITCHEN APPLIANCE sitting on the counter in between the stove and the sink' and 'What KIND OF SPORTING EQUIPMENT was against the wall' for high-typicality and low-typicality items, respectively). In addition, each cued recall question was followed by a remember/know judgment, which required participants to reflect on the qualities of their memories and decide whether they remembered associated details with their memory of the item or whether they just knew that the item they recalled was in the slides (Tulving, 1985). In addition to remember and know judgments, we included a guess judgment as participants were asked to report an item for all questions during the cued recall test.

\section{Design and procedure}

Three variables were manipulated in a 2 (event item: shown vs. not shown) $\times 2$ (misinformation: given vs. not given) $\times 2$ (typicality: high vs. low) within-participants design. Thus, the factorial design resulted in eight experimental conditions: contradictory misinformation when the misleading narrative contradicted an item that was present in the photographs (e.g., suggesting a toaster was in the kitchen when a coffee maker was actually present), additive misinformation when the misleading narrative merely added to the items present in the photographs (e.g., suggesting a toaster was in the kitchen when there was no small appliance in that part of the kitchen), misinformation control when an item was shown in the photographs and no misinformation was given, and guessing control when an item was neither presented nor suggested in the misleading narrative. These four conditions were reproduced for high-and lowtypicality items, and counterbalancing ensured that each item served in shown and suggested conditions equally often. 
The experimental procedure consisted of three phases: the event, the postevent, and the memory test. On arriving to the laboratory and after completing informed consent forms, participants were presented with the event phase of the experiment. Participants were instructed that the purpose of the experiment was to investigate how well people could visualize different scenes based either on viewing photographs of the scenes or reading narratives of the scenes. They were further instructed that in the first phase of the experiment they would be shown a series of photographs of common scenes and that they should attend to the photographs and try to remember as many details as possible. Participants then viewed a series of seven photographs for 15 seconds each. After the presentation of each photograph terminated, the computer screen would refresh and prompt the participant to rate how well they could now visualize the just-viewed scene on a 7-point Likert-type scale. The sequence of photographs followed the same order for all participants: computer lab, laundry room, kitchen, classroom, living room, automobile body shop, and bedroom. Afterwards, participants were required to complete find-word puzzles during a 10-minute delay period.

During the postevent phase, participants read narratives that described common scenes, some of which were the same as had been viewed in the photographic sequence. Again, participants were instructed that the purpose of this phase of the experiment was to ascertain how well people could visualize common scenes after having read a description of the scene. Participants read each narrative at their own pace, scrolling down the screen for narratives too long to be completely displayed all at once. After each narrative was read, the screen on the computer refreshed and prompted the participants to provide visualization ratings. After the participants read all the narratives, they were given another 10-minute filled delay period during which they completed find-word puzzles.

After the 10-minute delay period ended, participants were given a cued memory test on what they had seen in the photographs. Participants were explicitly instructed that the memory test referred to only what was seen in the photographs. Participants were also instructed on how to provide remember/know/guess judgments. Remember/know instructions were patterned after Rajaram (1993) with the addition of the guess judgments. Participants were instructed to indicate a guess response if they had no memory of the item in the scene and were purely guessing an item when prompted. The cued-recall test proceeded scene by scene with each screen shot displaying a single question. After participants indicated their response, the computer screen would refresh and prompt participants with a remember/know/guess judgment. After participants completed the cued recall test at their own pace, they answered basic demographic questions, and wrote brief definitions of remember and know judgments in their own words as an informal post-hoc check of their understanding of these measures.

\section{Results}

As our main interest centers on false memory as a result of misinformation, we first report analyses on false cued recall, followed by analyses of correct event cued recall. As we are interested in reports in which participants have the phenomenological experience that the item had been visually presented in the original scenes, we only conduct analyses on the remember and know responses with guess responses being treated as a non-response. Analyses were conducted on combined remember and know responses as an overall measure of event or false memory, as well as remember and know responses, separately. 
Table 1. Mean Proportion of False Remember and False Know Responses by Item Typicality, Type of Misinformation, and Condition

\begin{tabular}{lcccc}
\hline Condition & \multicolumn{2}{c}{ Additive } & \multicolumn{2}{c}{ Contradictory } \\
\hline Low & High & Low & High \\
Misled & & & & 0.01 \\
$\quad$ Remember & 0.06 & 0.03 & 0.11 & 0.00 \\
$\quad$ Know & 0.08 & 0.03 & 0.03 & 0.00 \\
Control & & & & 0.02 \\
$\quad$ Remember & 0.00 & 0.00 & 0.00 & -0.02 \\
$\quad$ Know & 0.02 & 0.01 & 0.00 & -0.02 \\
Difference & 0.06 & 0.03 & 0.11 & 0.03 \\
$\quad$ Remember & 0.06 & 0.02 & & \\
Know & & &
\end{tabular}

In order to investigate the effects of contradictory and additive misinformation with high and low typicality on false memory, we computed the difference scores between misinformation conditions and control conditions on the misled items that were falsely recalled for each participant. We used the difference scores to eliminate instances in which participants guessed the 'misinformation item' when they had in fact not been exposed to misinformation. Thus, the corrected CONTRADICTORY misinformation condition was computed by subtracting any reports of misinformation items of the misinformation control (shown event item/not given misled item) condition from the contradictory misinformation (shown/given) condition. ${ }^{1}$ As for the corrected ADDITIVE misinformation condition, the computation of false reports was a bit more complicated. Because critical-item reports in the guessing control (not shown/not given) condition could have represented misled items half of the time and event items half of the time, we assigned a 0.5 probability to each report occurrence. We then subtracted the false memory reports in the guessing control condition from the additive misinformation (not shown/given) condition. ${ }^{2}$ Analyses were performed on these difference scores.

Table 1 shows the mean proportion of false remember and know responses by item typicality, type of misinformation, and whether the participant was misled or not. Separate 2 (Misinformation: Contradictory vs. Additive) x 2 (Typicality: High vs. Low) repeated-measures ANOVAs were conducted on participants' combined remember and know responses, as well as remember and know responses separately for false recall of postevent misinformation. The ANOVA for combined false-remember and false-know responses of postevent misinformation indicated a main effect for item typicality only, $F(1,63)=10.96, p<0.001, \eta^{2}=0.15$. Participants were more likely to falsely report low-typicality items $(M=0.13, S D=0.24)$ in comparison to high-typicality items $(M=0.01, S D=0.18)$. Neither the main effect of misinformation nor the interaction between misinformation and typicality were significant, $F \mathrm{~s}(1,63)<1.03$, $p \mathrm{~s}$ $>0.31, \eta^{2} \mathrm{~s}<0.02$.

${ }^{1}$ For example, a participant who reported misinformation in the contradictory misinformation (shown event item/ given misinformation) condition and guessed the misinformation item in the misinformation control (shown event item/not given misinformation) would be scored $1-1=0$ for the corrected CONTRADICTORY misinformation condition.

${ }^{2}$ For example, a participant who reported misinformation in the additive misinformation (not shown event item/ given misinformation) condition and guessed a critical item in the guessing control (not shown event item/not given misinformation) condition would be scored $1-0.5=0.5$ for the corrected ADDITIVE misinformation condition. 
Separate analyses of false-remember and false-know responses resulted in a significant main effect of item typicality for false-remember responses (low-typicality items $M=0.09, S D=0.19$; high-typicality items $M=0.01, S D=0.14), F(1,63)=6.81, p<0.05$, $\eta^{2}=0.10$, and a main effect that approached significance for false-know responses (low-typicality $M=0.05, S D=0.17$; high-typicality $M=0.00, S D=0.12), F(1,63)=$ $3.40, p=0.07, \eta^{2}=0.05$. The two-way interactions between misinformation and item typicality were not significant regardless of whether examining only false remember or false know responses, $F_{\mathrm{s}}(1,63)<1.83$, $p \mathrm{~s}>0.18, \eta^{2}<0.03$.

We analyzed correct event recall in order to assess whether the presentation of misinformation for high-typicality items versus low-typicality items affected reports of shown items differentially. To measure event recall in an overall CONTROL condition, after correction for 0.5 probability, we subtracted reports of critical items in the guessing control (not shown/not given) condition from critical event items in the misinformation control (shown/not given) condition. In the MISLED condition, we subtracted critical event item reports in the additive misinformation (not shown/given) condition from the reports of critical event items in the contradictory misinformation (shown/given) condition. We conducted separate 2 (condition: misled vs. control) $x 2$ (item typicality: high vs. low) repeated-measures ANOVAs on correct event recall difference scores for the combined remember and know responses, as well as remember and know responses separately.

Significant findings were restricted to main effects of item typicality. None of the comparisons testing for a main effect of condition nor the condition by item typicality interaction were significant, $F_{s}(1,63)<1.13, p s>0.29, \eta^{2} s<0.02$. The ANOVA of the combined remember and know responses indicated a main effect of item typicality, $F(1,63)=16.09, p<0.001, \eta^{2}=0.20$, in which participants recalled more low-typicality event items $(M=0.34, S D=0.32)$ than high-typicality event items $(M=0.13, S D$ $=0.26$ ). Analyses conducted separately for remember and know responses revealed that the item-typicality effect was restricted to remember responses (low-typicality items $M=0.31, S D=0.32$; high-typicality items $M=0.11, S D=0.21 ; F(1,63)=19.90, p$ $\left.<0.001, \eta^{2}=0.24\right)$ as the main effect of item typicality was not significant for know responses $\left(F(1,63)=0.09, p=0.77, \eta^{2}=0.001\right)$.

\section{Discussion}

The most surprising finding of this study was the main effect of typicality on false memory. Misinformation of low-typicality items produced more false memory than high-typicality items. This finding appears to contradict the results of Roediger et al. (2001) who found greater false memory for high-expectancy items than low-expectancy items. In addition, this typicality effect of false memory included both false remember and false know responses. Thus, participants indicated greater false episodic detail regarding low-typicality items than high-typicality items. This suggests that misinformation of low-typicality items produces a 'strong' false memory effect given the significance of misinformation typicality on false remember responses.

The surprising nature of this finding warrants a closer inspection of Roediger et al.'s (2001) method. As mentioned previously, Roediger et al. manipulated the expectancy of an item within a particular scene. However, both high-and low-expectancy 
items were still schema consistent, just to varying degrees. In contrast, we manipulated whether the critical item in question was schema consistent or schema inconsistent via item typicality. Although this methodological difference alone does not explain the discrepancy in findings, the manipulation of expectancy versus typicality combined with the type of memory test employed may yield a clearer picture as to why we obtained disparate effects.

In the present experiment, we utilized a cued-recall measure of memory, whereas Roediger et al. (2001) used a free-recall procedure. The free-recall procedure may invoke the use of schematic knowledge at retrieval because participants are only given the very general cue of the scene name. Thus, in order to help remember the items that were present in the scene, the participant may mentally 'run-down' the list of items typically present in such scenes. As such, participants in the Roediger et al. study may have been more likely to incorporate misleading, high-expectancy items that the confederate fed to them than low-expectancy items. This may also be the reason why Brewer and Treyens (1981) found greater memory of schema-consistent items during recall of actual places, but found that participants were better at discriminating between present versus absent schema-inconsistent items in a recognition test of the same place. The recognition test provides a specific cue for the episodic detail of a scene, whereas the free-recall test provides a very general cue encouraging the reliance on general knowledge of a particular scene. Future research will need to address the demands that different memory tests produce on participants' reliance of general knowledge versus specific episodic detail with regard to the possible effects on the misinformation effect.

The comparison between contradictory versus additive misinformation failed to indicate a difference between these two types of misinformation when subtracting the control conditions. Frost (2000) found greater false remember responses for additive misinformation compared to contradictory misinformation but only after a 1-week delay. Thus, the retention interval (i.e., 10 minutes) utilized in this experiment may not be long enough for differences between these two misinformation conditions to exert their effects. Future research should explore variations in the retention interval to determine whether additive versus contradictory misinformation yield disparate effects only at longer retention intervals.

Concerning event memory, the findings of the present experiment confirm the basic typicality effect of recognition memory as seen in other research investigating the relationship between schematic knowledge and memory of complex visual scenes (Brewer \& Treyens, 1981; Friedman, 1979). Low-typicality event items shown in photographic scenes during the event phase of the experiment were better remembered than high-typicality event items. Although we used a cued-recall procedure and not a recognition test, both are similar in that they focus the participants' attention to some specific episodic detail in the visual scenes. As such, they do not invoke schematic retrieval as strongly as free-recall tests. What is surprising is the failure to find an interaction between type of misinformation (i.e., contradictory vs. additive) and item typicality. If low-typicality items are better remembered than high-typicality items in a cued-recall procedure, it seems likely that contradictory misinformation provided about these items would be detected and rejected by participants. However, our delay may have been too short for any interaction to occur as Frost (2000) only found a difference between additive and contradictory misinformation after a 1-week delay. Further investigations should determine whether this interaction can be found at longer retention intervals. 
The present research extends our knowledge of the misinformation effect by examining the role of schematic knowledge on the creation of false memories. Although Roediger et al. (2001) also examined the influence of schematic knowledge on the creation of false memories, the current study differs in three important ways. First, Roediger et al. utilized their innovative social-contagion paradigm, whereas we examined schematic knowledge in the traditional misinformation-effect paradigm. Second, Roediger et al., employed a free recall measure, whereas we used a cued recall procedure. As mentioned previously, free-recall measures have been shown to promote the use of schematic knowledge as an aid at retrieval (Brewer \& Treyens, 1981). Third, Roediger et al. manipulated variations of schema consistency (yet even low-expectancy items were still schema consistent) in what they dubbed expectancy. Our manipulations were more akin to manipulating schema-consistent versus schema-inconsistent items.

Quite possibly, expectancy and schema consistency may lie on a single continuum with high-expectancy items basically equaling high schema-consistent items on one end of the spectrum and schema-inconsistent items lying on the opposite end of the spectrum. On the other hand expectancy and schema consistency may reflect qualitatively different item dimensions. Although it may seem counterintuitive to have high-expectancy/schema-inconsistent items, it may be possible by introducing additional descriptive information about the scenes. For example, if the living room scene contains a low-typicality item such as a baseball bat or hockey stick, the participant could be informed that this is a living room of an athlete. In that case, the item might be expected, but still inconsistent with the scene. At any rate, regardless of whether a single continuum or separate dimensions, it is difficult to explain why high expectancy and schema inconsistency produce stronger misinformation effects than low-expectancy or schema-consistent items, respectively. These item dimensions may interact with the type of memory test given to measure the effect of misinformation.

The discrepancy between the results of the current study and Roediger et al. (2001) may be due to differences in the memory test that was used, differences in the source of the misinformation (i.e., confederate peer vs. experimenter), and the nature of how the schematic consistency of the items were manipulated. Future research will need to address which of these differences explains the discrepancy in findings. Nonetheless, the result that schema-inconsistent items are more likely to produce false remembering in cued-recall tests suggests a tantalizing new approach to the study of the misinformation effect. Just as manipulations of schema consistency may heighten event memory for schema-inconsistent items when memory tests cue episodic detail, similar manipulations of misinformation make for stronger false memories.

\section{Acknowledgments}

We thank Harlene Hayne and two anonymous reviewers for Applied Cognitive Psychology for helpful comments on an earlier version of this manuscript. We are grateful to Justin Wolfe and Yelena Kosheleva for their help with the programming and data collection of the experiment. This research was previously presented at the 44th Annual Meeting of the Psychonomic Society (2003), Vancouver, Canada. 


\section{References}

Belli, R. F., \& Loftus, E. F. (1996). The pliability of autobiographical memory: misinformation and the false memory problem. In D. C. Rubin (Ed.), Remembering our past: Studies in autobiographical memory (pp. 157-179). New York: Cambridge University Press.

Belli, R. F., Lindsay, D. S., Gales, M. S., \& McCarthy, T. T. (1994). Memory impairment and source misattribution in postevent misinformation experiments with short retention intervals. Memory \& Cognition, 22, 40-54.

Brewer, W. F., \& Treyens, J. C. (1981). Role of schemata in memory for places. Cognitive Psychology, 13, 207-230.

Erdfelder, E., \& Bredenkamp, J. (1998). Recognition of script-typical versus script-atypical information: effects of cognitive elaboration. Memory \& Cognition, 26, 922-938.

Friedman, A. (1979). Framing pictures: the role of knowledge in automatized encoding and memory for gist. Journal of Experimental Psychology: General, 108, 316-355.

Frost, P. (2000). The quality of false memory over time: is memory for misinformation 'remembered' or 'known'? Psychonomic Bulletin E Review, 7, 531-536.

Lindsay, D. S. (1994). Memory source monitoring and eyewitness testimony. In D. F. Ross, J D. Read, \& M. P. Toglia (Eds.), Adult eyewitness testimony: Current trends and developments (pp. 27-55). New York: Springer-Verlag.

Lindsay, D. S. (1990). Misleading suggestions can impair eyewitnesses' ability to remember event details. Journal of Experimental Psychology: Learning, Memory, E Cognition, 16, 1077-1083.

Loftus, E. F. (1975). Leading questions and the eyewitness report. Cognitive Psychology, 7, 560-572.

Loftus, E. F., \& Palmer, J. E. (1974). Reconstruction of automobile destruction: an example of the interaction between language and memory. Journal of Verbal Learning and Verbal Behavior, 13, 585-589.

Loftus, E. F., Donders, K., Hoffman, H. G., \& Schooler, J. W. (1989). Creating new memories that are quickly accessed and confidently held. Memory $\mathcal{E}$ Cognition, 17, 607-616.

Loftus, E. F., Miller, D. G., \& Burns, H. J. (1978). Semantic integration of verbal information into a visual memory. Journal of Experimental Psychology: Human Learning $\mathcal{E}$ Memory, 4, 19-31.

Meade, M. L., \& Roediger, H. L. (2002). Explorations in the social contagion of memory. Memory \& Cognition, 30, 995-1009.

Rajaram, S. (1993). Remembering and knowing: two means of access to the personal past. Memory \& Cognition, 21, 89-102.

Roediger, H. L., III, Meade, M. L., \& Bergman, E. T. (2001). Social contagion of memory. Psychonomic Bulletin \& Review, 8, 365-371.

Tulving, E. (1985). Memory and consciousness. Canadian Psychologist, 26, 1-12.

Zaragoza, M. S., \& Lane, S. M. (1994). Source misattributions and the suggestibility of eyewitness memory. Journal of Experimental Psychology: Learning, Memory, \& Cogntion, 20, 934-945.

Zaragoza, M. S., Belli, R. F., \& Payment, K. E. (in press). Misinformation effects and the suggestibility of eyewitness memory. In M. Garry, \& H. Hayne (Eds.), Retrospection: Elizabeth Loftus's contributions to basic and applied problems in human memory. Erlbaum. 


\section{Appendix A}

High- and Low-Typicality Critical Items By Critical Scene

\begin{tabular}{lll}
\hline Scene & \multicolumn{1}{c}{ Item Typicality } \\
\cline { 2 - 3 } & \multicolumn{1}{c}{ High } & \multicolumn{1}{c}{ Low } \\
\hline Kitchen & Toaster $(M=7.00, S D=0.00)$ & $\begin{array}{l}\text { Stapler }(M=2.17, S D=1.52) \\
\text { Tape dispenser }(M=2.18, S D=1.61) \\
\end{array}$ \\
& Coffee Maker $(M=6.96, S D=0.20)$ & Toilet paper $(M=3.33, S D=2.71)$ \\
& Apples $(M=6.88, S D=0.45)$ & Shampoo $(M=3.54, S D=2.13)$ \\
Living & Coat $(M=5.25, S D=1.45)$ & Wrench $(M=2.29, S D=1.52)$ \\
Room & Sweater $(M=5.33, S D=1.37)$ & Hammer $(M=2.33, S D=1.52)$ \\
& Book $(M=6.29, S D=0.91)$ & Baseball bat $(M=3.46, S D=1.62)$ \\
& Newspaper $(M=6.38, S D=0.93)$ & Hockey stick $(M=2.92, S D=1.61)$ \\
\hline
\end{tabular}

Means and standard deviations for typicality ratings are indicated in parentheses.

\section{Appendix B}

\section{Example of Narrative for the Living Room Scene}

The living room scene depicted is that of a fairly typical living room scene in the United States. The walls are a white color and the carpet is a grayish tan. To keep the general color scheme consistent, the upholstery on a couch and a love seat is also light gray. To the back of the living room there is a screened patio door that leads to a deck. A green fern sitting on the floor breaks the monotony of the white and gray colors, and brings life and interest to the otherwise empty area in front of the patio door. Another element of interest in this room is a mounted pheasant, which is placed on the wall about 3-4 feet above the floor to the right from the patio door. A TV on a stand is angled in the corner to make sure that the screen is seen well from both couches. The TV stand also houses several electronic accessories such as a cable box and a DVD player.

Against the right wall one can see a full sized stereo with several smaller objects grouped on and next to it, such as an athletics trophy, (a baseball bat, a hockey stick, $\mathbf{x})$, a CD organizer, some individual CDs, and DVDs in cases. Above the stereo you can see part of a painting. On the floor between the coffee table and couch there is a pair of shoes (and a hammer, a wrench, $\mathbf{x}$ ). There is the usual clutter on the coffee table: three remote controls, several magazines, (a book, a newspaper, $\mathbf{x}$ ), several CDs, a jar, and also a telephone. In the corner there is an armchair that has a blanket on it in front of a lamp. The lamp is turned on and emits soft yellow light. On the couch next to the coffee table there are several cushions, (a coat, a sweater, $\mathbf{x}$ ), and on the wall there is another painting. [Note: Possible misinformation is in bold-face type. $\mathrm{X}$ indicates no misinformation.] 